\title{
Oil Price Fluctuation, Gold Returns and Inflationary Pressure: An Empirical Analysis Using Cointegration Approach
}

\author{
Hanan Naser \\ Correspondence: Hanan Naser, Department of Business Studies, Arab Open University, Bahrain. \\ Received: December 29, 2018 \\ Accepted: January 31, $2019 \quad$ Available online: February 13, 2019 \\ doi:10.11114/aef.v6i2.4054 \\ URL: https://doi.org/10.11114/aef.v6i2.4054
}

\begin{abstract}
Given that oil and gold prices are the major representative for commodity market, they both play a crucial role in determining the level of consumption, industrial production and investment due to the direct effect by the changes in their prices. In addition, both oil and gold prices have inflationary pressure which has a direct impact on countries economic growth. Therefore, it is of crucial practical significance to analyze their cointegration relationships to understand the co-movement of both prices. To do so, this paper aims to examine the impact of oil price fluctuation on gold prices taking into account the inflationary pressure in the United States (US). Using monthly data from April, 1986 to September, 2018, Johansen multivariate cointegration test procedure and vector error correction model (VECM) have been employed to examine the long-run relationship between the variables in the US. The key findings suggest that there is a significant positive long run relationship between crude oil prices, gold prices and inflation. In the short run, the impact of any changes in crude oil prices will have a delayed effect on the prices of gold, while the impact of inflation in not different from zero. In addition, both gold prices and inflation are found to have no impact on gold prices in the short run. The findings of this research are important for investors, portfolio managers, corporate houses, crude oil traders, the government and policy makers.
\end{abstract}

Keywords: crude oil prices, gold prices, inflation, cointegration

\section{Introduction}

It is not surprising to find that oil prices have stunning influence on every single aspect of the rest of economy. For the periods that witness high surge of oil prices, inflationary pressure pumps up the prices of almost every item in the economy. Accordingly, the inflationary channel can simply brings to the attention the fact that increases in gas prices occurs when the price of oil increases. ${ }^{1}$ This in fact increases the cost of goods transportation from a point to another, where the increment is then transferred to the consumer thought the rise of goods and services. Looking at the precious metals, precisely gold, it is very clear that gold is not only an important asset that has been a storehouse of wealth for thousands of years, but it also holds its value at bust periods, which make it very attractive for governments and investors. In literature, many studies have suggested that gold is a crucial asset that can minise risk and play a vital role in hedging against inflation. ${ }^{2}$

Typically, having great plung in oil prices might be a sign for an upcoming recession. As much as the periods of lower oil prices increases, it becomes more likely to have a severe recession or even a depression. Yet, there will be a turning point where this period will end by having up trended oil prices. This normally signals economic growth and produces inflation, which is consistent with a growing economy. It is worth to note that if oil prices increase sharply, it can produce extensive inflation pressure in any economy, which may directly affect the gains in gold market. Therefore there is a high demand to keep on not only monitoring the co-movement of oil and gold prices, but also to investigate the nature of the relationship among them taking into account the inflationary pressure. This in fact would help the policy designers and investors to design more effective economic plans and strategies. To my knowledge, most studies in literature have focused on the relationship between oil and gold only, where others tackled this impact on stock

\footnotetext{
1 Several studies have established the linkage between oil prices and inflation. Among others, see (Hunt, 2006); (Hooker \& Banking, 2002))

2 For more discussion on this issue, see (Capie, Mills, Wood, \& Money, 2005) and (H. Naser, 2017)
} 
market. This paper aims to investigate the long run relationship among oil and gold prices taking into account the inflationary pressure.

\section{Literature Review}

In literature, a study by (Narayan, Narayan, \& Zheng, 2010) finds that there is a strong evidence of a long-run relationship between the futures markets of gold and oil, and oil spot over different maturities. Authors have claimed that the increase in the prices of oil, will lead to an inflationary pressure and thus force investors to take more defensive steps to protect their investment portfolios by investing in some financial assets such as gold.

(Zhang \& Wei, 2010) has shed the light on both short and long run relationship between gold and crude oil prices. They find that the trends between both series are consistent where the relationship is not only positive, but significant among the full period. It has been suggested the volatility of gold prices is attributed to the change in oil prices in the short term. In another words, oil prices are found to have greater impact than gold prices.

Using monthly data from May 1994 to April 2011, (Le \& Chang, 2013) have examined the impact of oil price on the market of gold using vector autoregressive model (VAR). The key outcome from this study has claimed that the shocks of oil price shocks have significant and positive impact on real gold markets.

Looking at different data-sets that allow for taking into consideration the unique characteristics, (Kumar, 2017) has investigated the nature of the linkage between gold and oil prices in India using Autoregression Distributed Lag (ARDL) model. He has suggested that there is a short and long term relationship between the two variables, where a strong bidirectional nonlinear relation between gold and oil prices has been detected.

To tackle the hedging purpose, a study by (Reboredo \& Finance, 2013) and (H. J. I. J. o. E. Naser \& Issues) have analysed the potential of gold to hedge against changes in oil price. Using United States (US) data, she has suggests that gold investments in the US provide an effective hedge against inflation for investors who are willing to keep their investments for long-run, while its impact in the short term is not different from zero.

\section{Methodology}

Before conducting cointegration analysis, stationary tests are essential for identifying the order of integration of the proposed variables. The most popular tests in literature are the Augmented (D. A. Dickey \& W. A. J. J. o. t. A. s. a. Fuller, 1979) (Dickey \& Fuller, 1981) (ADF). The ADF (augmented Dickey-Fuller) testing procedure tests the unit root hypothesis as following:

$$
\Delta y_{t}=\theta_{0}+\gamma_{0} t+\gamma_{1} y_{t-1}+\sum_{i=0}^{p} \theta_{i} \Delta y_{t-1}+\varepsilon_{t}
$$

where $y_{t}$ is the variable in period $\mathrm{t} ; \Delta y_{t-1}$ the $y_{t-1}-y_{t-2} ; \varepsilon_{t}$ is the i.i.d. disturbance with mean 0 and variance $1 ; \mathrm{t}$ the linear time trend and $\mathrm{p}$ is the lag order. In order to test the null hypothesis for the presence of a unit root in $y_{t}$, the hypothesis testing that $\gamma_{1}=0$ in Equation 1 was conducted. If $\gamma_{1}$ is significantly less than zero, the null hypothesis of a unit root is rejected. Since selecting the number of optimal lags, $\mathrm{k}$, is a crucial issue for conducting a stable cointegration model, this paper uses three different test including Akaike (AIC), Hannan and Quinn (HQIC), and Schwarz's Bayesian (SIC) information criteria to build a final decision. Once all variables are integrated of the same order, this study proceeds to examine the existence of long-run relationship(s) among series. Precisely, a cointegration methodology that starts with a general approach and move to a more specific is applied to estimate the long-run relationship(s) between the variables included in vector $\mathrm{Zt}$, where $\mathrm{Zt}$ includes a number of integrated series at the same level. To do so, long-run relationships between the variables included in vector $\mathrm{Zt}$ are estimated using Johansen Maximum Likelihood approach. Specifically, one can write $\mathrm{Zt}$ as a vector autoregressive process of order k (i.e., VAR $(\mathrm{k}))$ :

$$
\begin{gathered}
Z_{t}=A_{0}+\sum_{i=1}^{k} A_{i} Z_{t-i}+u_{t} \\
\Delta Z_{t}=A_{0}+\prod Z_{t-1} \sum_{i=1}^{k} \Gamma_{i} \Delta Z_{t-i}+u_{t}
\end{gathered}
$$

Where Zt denotes $(3 \times 1)$ vector containing Gold prices, real oil prices $(\mathrm{WTI})$, and inflation $(\mathrm{Zt}=(\mathrm{GOLDt}$; WTIt; INFt)). The three variables are measured by their natural logarithm where their first difference approximates their returns. Any long-run relationship(s) are captured by the $(3 \times 3)$ matrix $\Pi$ shown in Equation (3). To examine the long-run relationship (s) between the suggested variables, (S. Johansen, 1988) test has been established in order to test 
for the existence of $\mathrm{r} \leq 2$ cointegration relationships among the three variables of the model. ${ }^{3}$ This is equivalent to testing the hypothesis that the rank of matrix $\Pi$ in Equation (3) is at most r. Reduced-rank regression can then be used to form a likelihood ratio test of that hypothesis on the basis of the so-called trace statistic, or alternatively, the maximum eigenvalue statistic. (Lütkepohl, Krätzig, \& Phillips, 2004) investigate the small sample properties of both tests and conclude that the trace testis slightly superior, and therefore, we favor it in our analysis. Thus, the rank of the matrix $\Pi$ is imposed to estimate the un-restricted model shown in Equation (3). However, this matrix (i.e. П) can be decomposed as shown below in Equation (4) to provide better understanding for the full system:

$$
\Delta Z_{t}=A_{0}+\alpha \beta^{\prime} Z_{t-1} \sum_{i=1}^{p} \Gamma_{i} \Delta Z_{t-i}+u_{t}
$$

where the cointegrating vectors are presented in a $(3 \times \mathrm{r})$ matrix named $\beta$ and the speed of adjustments are shown in a $(3 \times \mathrm{r})$ matrix called $\alpha$. $\Gamma$ i represents $(3 \times 3)$ matrices that guide short run dynamics of the model and $u_{t}$ is iid $\sim N$ $(0, \Sigma)$.

\section{Empirical Results}

\subsection{Data}

This study uses the US data to investigate the long-run relationship among gold prices, oil prices and inflation. It uses monthly data on gold investment proxied by gold prices (Gold), WTI real prices (WTI) and inflation measured by consumer price index (INF), between April 1986 and September 2018. The data are collected from FRED database for consumer price index, where it represents the consumer Price Index for All Urban Consumers: All Items, Index 1982-1984=100, and seasonally adjusted. Gold prices are collected from the ICE Benchmark Administration Limited (IBA) on the basis of US dollars. Real oil price is defined as the US dollar prices of oil and deflated by the domestic consumer price index (CPI), which is derived from International Financial Statistics (IFS, 2009) published by the International Monetary Fund (IMF).

All data are expressed in natural logarithms to proceed with our empirical investigation. Figure 1, Figure 2 and Figure 3 plot oil prices (WTI), gold prices (GOLD) and consumer price index (INF) at level, respectively, for the period from April 1986 till September 2018.

Looking at crude oil prices shown in Figure 1, the massive increase tells a story. Originally, oil was traded because it is an essential energy source. However, it recently gained a solid place in the investment portfolio and hence, deviated the price determination from being mainly derived from the relationship between the global demand and supply into other factors such as speculation and politics. According to literature, the oil market is differentiated from other commodity market by certain facts. Oil market shows substantial deviation from the perfect market, where the price range is just above marginal costs. There are many reasons behind that as discussed in literature. Primarily, the leading producers have attempted to control the market by restricting both, the production quota and selling prices. Quoting price of oil affects the pricing of all major oil producers and they regulate the supply of oil in order to achieve price targets. This market is also largely determined by political factors and internal situations in major producing and consuming countries, as well as international conflicts and tensions. Over time, few main production and consumption centers were formed from different parts of the world with their own quoting price. On the basis of the mining areas (North Sea crude oil market, Russian oil market, etc.) and commodity exchange centers (IPE, NYMEX, etc.), the main centers of production and consumption have shaped the spot markets. The differences in the prices of the crude oil from different centers is varying due to the differences in quality and transportation cost. However, the correlation and reaction between prices in these markets are very high. Price development in the years 1986 to 2018 can be seen in Figure 1. Since rising oil prices typically send us an early inflation signal, gold prices tend to soar as shown Figure 2, where Figure 3 shows that the inflation has always been upward trended.

\footnotetext{
${ }^{3}$ For more information see (S. J. J. o. e. d. Johansen \& control, 1988), (S. Johansen, Juselius, \& statistics, 1990), (S. J. O. B. o. E. Johansen \& Statistics, 1992).
} 


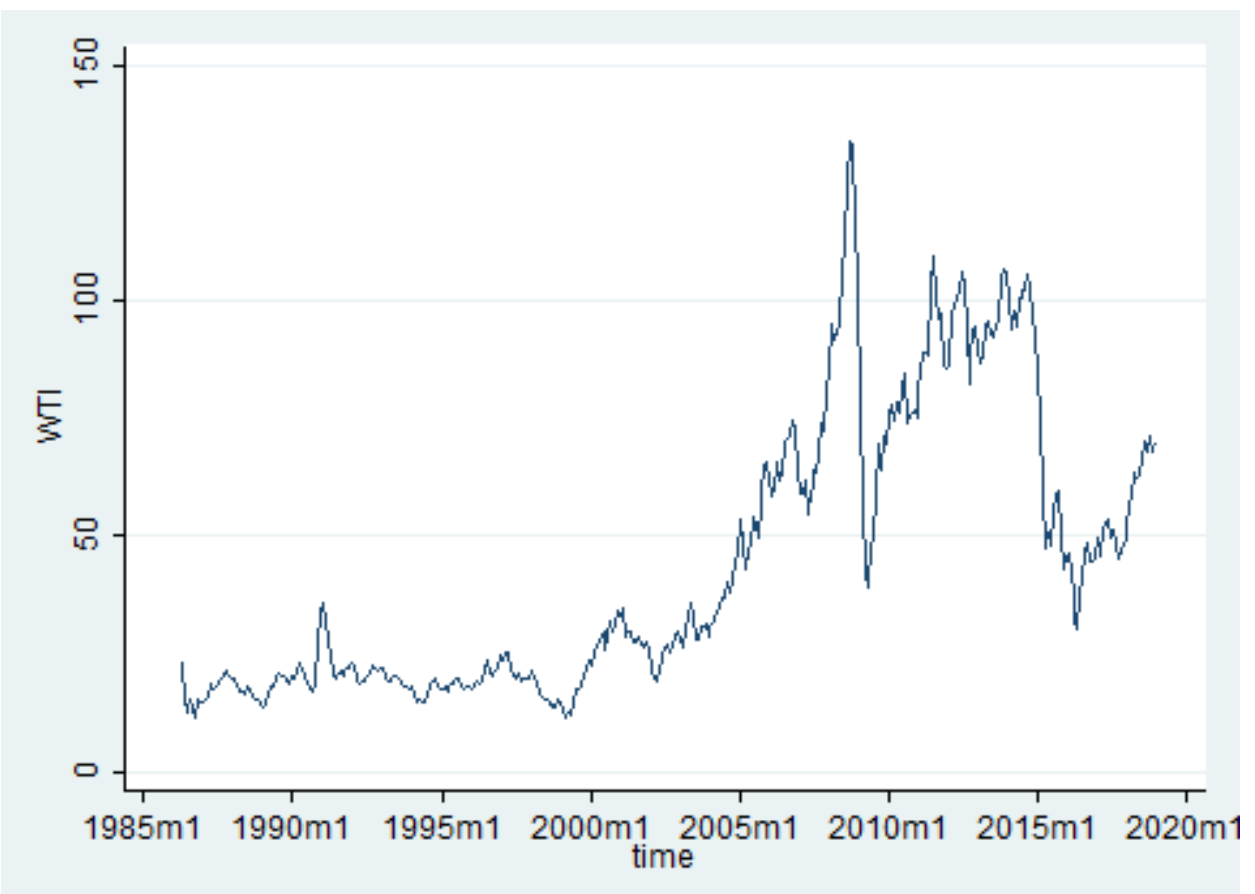

Figure 1. Plot of WTI oil prices

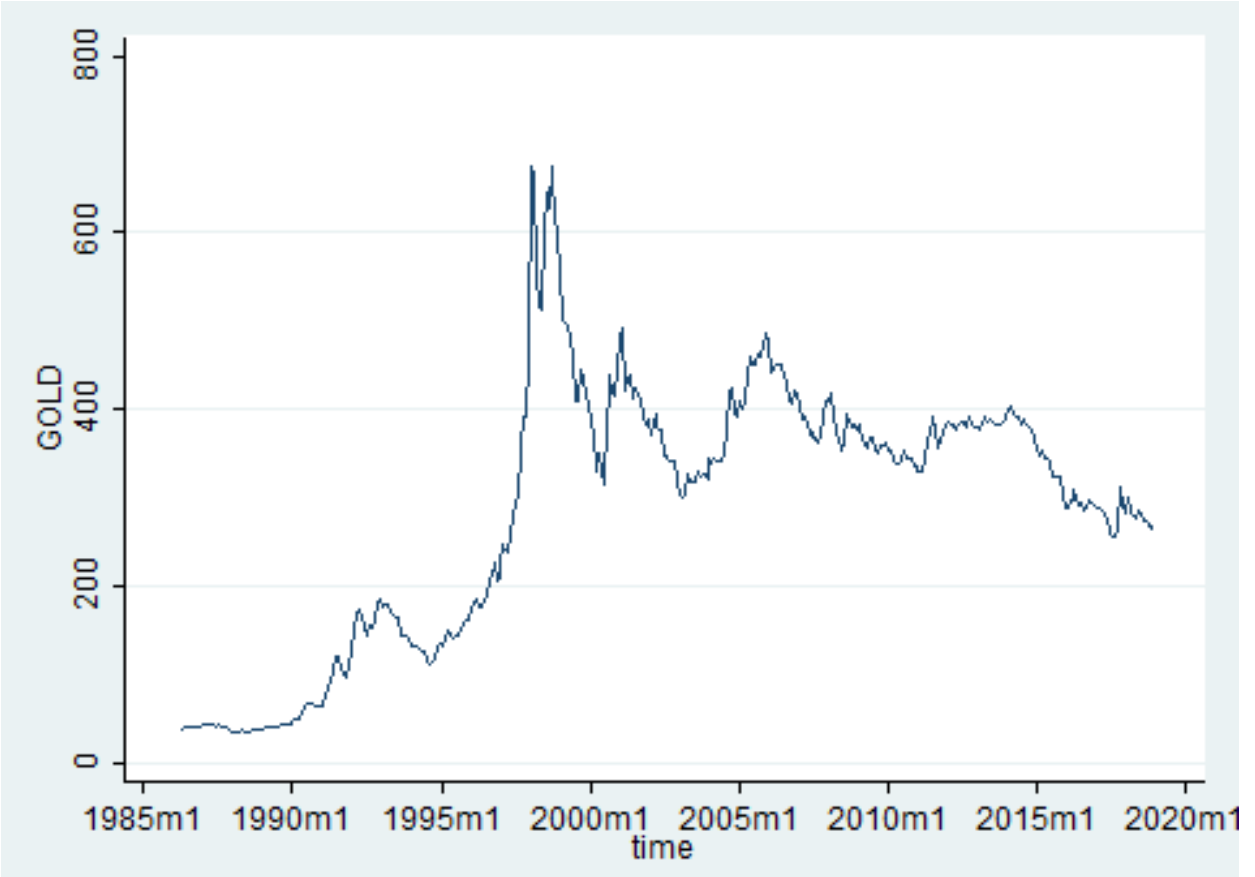

Figure 2. Plot of Gold prices 


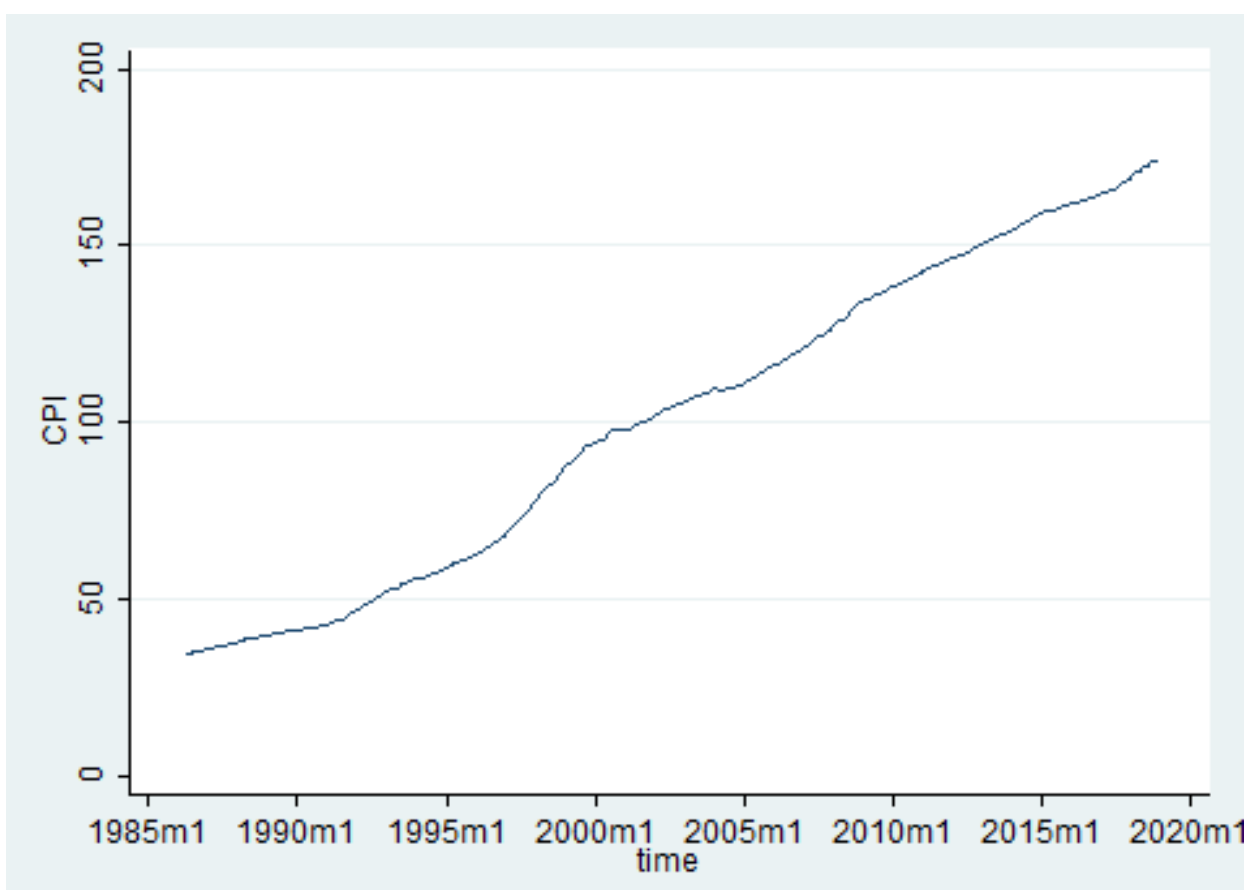

Figure 3. Plot of CPI

Descriptive statistics shown in Table 1 provides means to describe the basic feature and structure of available data. The various descriptive statistical measures mean, standard deviation, skewness, and kurtosis have been used to identify and summarize the general trends of the data-set.

Table 1. Descriptive statistics: Monthly data

\begin{tabular}{llll}
\hline Variable & Gold & WTI & CPI \\
\hline Mean & & & 1.953 \\
\hline SD & 2.356 & 1.545 & 0.221 \\
\hline Skewness & & & -0.471 \\
\hline Kurtosis (excess) & 0.349 & 0.287 & $(0.000)$ \\
\hline
\end{tabular}

4.2 Results and Discussion

Stationarity Test: Before conducting the cointegration test, the data series should be examined for stationarity in order to confirm the order of integration of each variable. In this paper, Augmented (D. A. Dickey \& W. A. J. J. o. t. A. s. a. Fuller, 1979) (ADF) is applied to confirm the integration order. In Table 2, the null hypothesis of no unit roots for all the time series are rejected at their first differences since the ADF test statistic values are less than the critical values at $5 \%$ levels of significance. Thus, the variables are non stationary and integrated of same order, i.e., I (1). All variables became stationary and do not contain unit root in first difference as shown below in Table 2 .

Table 2. Unit root test

\begin{tabular}{lll}
\hline \multirow{2}{*}{ Variable } & ADF & First difference \\
\cline { 2 - 3 } Gold & Level & $-14.293 * * *$ \\
\hline WTI & 1.183 & $-15.43^{* * *}$ \\
\hline CPI & & $-9.005^{* * *}$ \\
\hline
\end{tabular}


Note: Table 3 entries are the results obtained from unit root tests. Tests are shown in the first row: augmented (D. A. Dickey \& W. A. Fuller, 1979) (ADF). Regression includes an intercept and trend. The variables are specified in the first column: gold price (Gold), crude oil price (WTI) and consumer price index (CPI). All variables are in natural logarithms, while the lag length determined by Akaike Information Criteria and are in parentheses. '*' and '**' indicate significance at the $10 \%$ and $5 \%$ level, respectively.

Determination of Lags: Table 3 reports lag-order selection statistics, which shows that the optimal lag length for the tested system is two. This indeed suggest that the empirical work should be proceeded using lags (2) as guided by the Akaike Information Criterion (AIC), Schwarz's Bayesian information criterion (SBIC), and the Hannan and Quinn information criterion (HQIC).

Table 3. Selection- order criteria

\begin{tabular}{llll}
\hline Lags & AIC & HQIC & SBIC \\
\hline 0 & -1.623 & -1.611 & -1.592 \\
1 & -19.383 & -19.334 & -19.259 \\
2 & -19.781 & $-19.694^{*}$ & $-19.563^{*}$ \\
3 & $-19.813^{*}$ & -19.689 & -19.502 \\
4 & -19.806 & -19.646 & -19.402 \\
\hline
\end{tabular}

Notes: AIC, HQIC and SBIC stand for Akaike, Hannan and Quinn and Schwarz's Bayesian information criteria, respectively.

Cointegration Test and VECM: Since all the series are nonstationary in level and integrated of the same order, I(1), this suggests a possibility of the presence of cointegrating relationship among variables. In order to explore such a possibility, Johansen cointegration tests (Johansen, 1988 and Johansen and Juselius, 1990) are performed to test for the existence of cointegrating relationships between each pair: Gold prices, oil prices and inflation. As pre-test of the testing procedure, logged variables are entered as levels into VAR models with different lag lengths and F-tests are used to select the optimal number 16 of lag lengths needed in the cointegration analysis. The lag selection is guided by the Akaike Information Criterion (AIC), Schwarz's Bayesian information criterion (SBIC), and the Hannan and Quinn information criterion (HQIC).

Table 4. Johansen cointegration estimation between gold, wti and inflation

\begin{tabular}{llll}
\hline Number of cointegration & Eigenvalue & Trace Statistics & 5\% Critical Value \\
\hline None & $\cdot$ & 73.782 & 34.55 \\
At most 1 & 0.145 & $12.541^{*}$ & 18.17 \\
At most 2 & 0.03 & 0.508 & 3.74 \\
At most 3 & 0.001 &. &. \\
\hline
\end{tabular}

As suggested by by (S. J. J. o. e. d. Johansen \& control, 1988), the results of testing for the number of cointegrating vectors are reported in Table 4, where $\pi$ is representing the number of cointegration vectors. Basically, $\pi$ is derived from two likelihood estimators, where the first named Eigen value and the second known as trace statistics test. The cointegration rank (r) can be formally tested with the trace and Eigen value statistics taking into accounts the 5\% critical value of the test. Thus, results shown in Table 4 reveal that the trace statistic either rejects the null hypothesis of no co-integration among the variables or does not reject the null hypothesis that there is one co-integration relation between the variables. Start by testing a maximum rank of 0 , if it is rejected, then repeat for next option where the maximum rank tested for 1 . When a test is not rejected, then stop testing there and that value of $r$ is the commonly-used estimate of the number of cointegrating relations. Here, $r=1$ is not rejected at the $5 \%$ level. In other words, this trace test result does not reject the null hypothesis that these two variables are not cointegrated. The final number of cointegrated vectors with two lags is equal to one, i.e. $\operatorname{rank}(r)=1$. Since, the rank is equal to 1 which is more than zero and less than the number of variables; the series are cointegrating among the variables. Nevertheless, we will proceed to estimate the ECM model to estimate the short-run dynamics.

By applying the ECM model, results shown in Table 5 report the long-run elasticities, where cointegration tests show that all the variables under our examination are co-integrated at $5 \%$ significance level. This in fact suggests that there is not only a positive long run relationship between gold prices, real oil prices (WTI) and inflation, but also both WTI and CPI are significantly affecting the level of gold prices in the long-run. More precisely, an increase of $1 \%$ in crude oil prices increases the price of gold by $0.29 \%$, where an increase of $1 \%$ in consumer price index (CPI) significantly 
increases gold prices by $0.57 \%$. As the long-run elasticity of the later is inelastic, it suggests hat gold prices rise in response to inflationary pressure but not as much as increases in inflation.

Looking at the lower part of Table 5, the second column represents the coeiffients of short run estimation for gold return equation. It is clear that both lags of gold and crude oil prices affect the level of spot gold prices while inflation has no significant impact. However, the impact of the first lag of crude oil price is not different from zero which suggest that the influence on the price level of gold is delayed and thus significant at $5 \%$ level for the send lag $(\Delta \mathrm{WTI}(-2))$. Looking at the third column of the same table, it is very clear that none of gold prices or inflation have any impact on crude oil price level at short run.

Table 5. VECM estimation results

\begin{tabular}{|c|c|c|c|}
\hline Cointegration equations & \multicolumn{3}{|c|}{ Cointegrating Eq. (1) } \\
\hline Gold & \multicolumn{3}{|l|}{1} \\
\hline WTI & \multicolumn{3}{|l|}{$0.290 * *$} \\
\hline CPI & \multicolumn{3}{|l|}{$0.571 * * *$} \\
\hline Vector Error Correction & $\Delta$ Gold & $\Delta \mathrm{WTI}$ & $\Delta \mathrm{CPI}$ \\
\hline \multirow{2}{*}{$\Delta$ Gold $(-1)$} & $0.341 * * *$ & 0.019 & $0.002 * *$ \\
\hline & $(0.001)$ & $(0.819)$ & $(0.033)$ \\
\hline \multirow{2}{*}{$\Delta$ Gold (-2) } & $-0.0169^{* *}$ & 0.045 & $0.009^{*}$ \\
\hline & $(0.0403)$ & $(0.584)$ & $(0.068)$ \\
\hline \multirow{2}{*}{$\Delta \mathrm{WTI}(-1)$} & 0.021 & $0.258^{* * *}$ & $0.001 * *$ \\
\hline & $(0.611)$ & $(0.000)$ & $(0.028)$ \\
\hline \multirow{2}{*}{$\Delta \mathrm{WTI}(-2)$} & $0.024 * *$ & 0.016 & $0.002 * *$ \\
\hline & $(0.021)$ & $(0.743)$ & $(0.012)$ \\
\hline \multirow{2}{*}{$\Delta$ CPI $(-1)$} & $0.246^{*}$ & 0.877 & $0.457 * * *$ \\
\hline & $(0.046)$ & $(0.622)$ & $(0.000)$ \\
\hline \multirow{2}{*}{$\Delta$ CPI (-2) } & 0.676 & 2.245 & $0.282 * * *$ \\
\hline & $(0.119)$ & $(0.211)$ & $(0.000)$ \\
\hline \multirow{2}{*}{ ECT_t-1 } & $-0.004 * *$ & $0.008 * * *$ & $0.004 * * *$ \\
\hline & $(0.021)$ & $(0.000)$ & $(0.000)$ \\
\hline
\end{tabular}

Notes: '***' indicate significance at $1 \%$ level, ‘**' indicate significance at $5 \%$ level and '*' indicate significance at $10 \%$ level

\section{Concluding Remarks}

Gold and crude oil are not only the most traded commodities among the world, but also play vital role in global economy. Precisely, whenever the price of oil witness any obvious increase, it is expected to affect the prices of all the other goods and services that are related to oil. In addition, as diesel has been always considered as the main fuel used in transport industry, it is the key factor in deciding the prices of food (vegetables and fruits) and other commodities, and hence put more inflationary pressure in economies. To hedge against inflation, investors start buying gold that further results in increase in demand and hence the price of gold.

The present study aims to investigate the linkage between gold, crude oil prices and inflation using monthly data from April 1986 till September 2018. The results show that there is a significant positive correlation (0.290) between crude oil and gold prices, on one hand. On the other hand, the cointegration equation shows that the inflation and gold prices are strongly correlated $(0.571)$. The lower part of Table 5 reveals that the short run estimation of Johansen's cointegration indicate that the short run impact of any changes in crude oil prices will have a delayed effect on the prices of gold, while the impact of inflation in not different from zero at short run. However, gold prices and inflation are found to have no impact on gold prices in the short run.

The findings of this research are important to the investors, portfolio managers, corporate houses, crude oil traders, the government and policy makers. 


\section{References}

Capie, F., Mills, T. C., Wood, G. J. (2005). Gold as a hedge against the dollar. J. I. F. M., Institutions, \& Money, 15(4), 343-352. https://doi.org/10.1016/j.intfin.2004.07.002

Dickey, D. A., \& Fuller, W. A. (1979). Distribution of the estimators for autoregressive time series with a unit root. Journal of the American statistical association, 74(366a), 427-431. https://doi.org/10.1080/01621459.1979.10482531

Dickey, D. A., \& Fuller, W. A. (1979). Distribution of the estimators for autoregressive time series with a unit root. 74(366a), 427-431.

Dickey, D. A., \& Fuller, W. A. (1981). Likelihood ratio statistics for autoregressive time series with a unit root. 1057-1072. https://doi.org/10.2307/1912517

Hooker, M. A.. (2002). Are oil shocks inflationary? Asymmetric and nonlinear specifications versus changes in regime. 540-561. https://doi.org/10.1353/mcb.2002.0041

Hunt, B. (2006). Oil price shocks and the US stagflation of the 1970s: Some insights from GEM. 61-80.

Johansen, S. (1988). Statistical analysis of cointegration vectors. Journal of economic dynamics and control, 12(2-3), 231-254. https://doi.org/10.1016/0165-1889(88)90041-3

Johansen, S. (1988). Statistical analysis of cointegration vectors. 12(2-3), 231-254. https://doi.org/10.1016/0165-1889(88)90041-3

Johansen, S. (1992). Determination of cointegration rank in the presence of a linear trend. 54(3), $383-397$. https://doi.org/10.1111/j.1468-0084.1992.tb00008.x

Johansen, S., \& Juselius, K. (1990). Maximum likelihood estimation and inference on cointegration-with applications to the demand for money. 52(2), 169-210. https://doi.org/10.1111/j.1468-0084.1990.mp52002003.x

Kumar, S. (2017). On the nonlinear relation between crude oil and gold. 51, 219-224. https://doi.org/10.1016/j.resourpol.2017.01.003

Le, T. H., \& Chang, Y. (2013). Oil price shocks and trade imbalances. J. E. E., 36, 78-96. https://doi.org/10.1016/j.eneco.2012.12.002

Lütkepohl, H., Krätzig, M., \& Phillips, P. C. (2004). Applied time series econometrics: Cambridge university press. https://doi.org/10.1017/CBO9780511606885

Narayan, P. K., Narayan, S., \& Zheng, X. (2010). Gold and oil futures markets: Are markets efficient? J. A. e., 87(10), 3299-3303.

Naser, H. (2017). Can Gold Investments Provide a Good Hedge Against Inflation? An Empirical Analysis. 7(1), 470-475.

Naser, H. J. I. Can Gold Investments Provide a Good Hedge Against Inflation? An Empirical Analysis. 7(1), $470-475$.

Reboredo, J. C. (2013). Is gold a safe haven or a hedge for the US dollar? Implications for risk management. J. J. O. B., \& Finance, 37(8), 2665-2676. https://doi.org/10.1016/j.jbankfin.2013.03.020

Zhang, Y. J., \& Wei, Y. M. (2010). The crude oil market and the gold market: Evidence for cointegration, causality and price discovery. J. R. P., 35(3), 168-177. https://doi.org/10.1016/j.resourpol.2010.05.003

\section{Copyrights}

Copyright for this article is retained by the author(s), with first publication rights granted to the journal.

This is an open-access article distributed under the terms and conditions of the Creative Commons Attribution license which permits unrestricted use, distribution, and reproduction in any medium, provided the original work is properly cited. 